\title{
Classificação de fragmentos florestais urbanos com base em métricas da paisagem
}

\author{
Classification of urban forest fragments based on landscape metrics
}

\author{
Alessandra Leite da Silva ${ }^{\mathrm{I}}$, Regina Márcia Longo ${ }^{\mathrm{II}}$, Adriano Bressane ${ }^{\mathrm{III}}$, Marcius \\ Fabius Henriques de Carvalho ${ }^{\text {II }}$
}

\begin{abstract}
Resumo
A urbanização no município de Campinas-SP e região ocorreu de forma rápida e intensa, provocando acentuadas alterações na paisagem e resultando em uma expressiva degradação das áreas florestais e da cobertura vegetal natural. Este fenômeno deu origem a um processo de fragmentação florestal bastante intenso. Neste contexto, mapear estes fragmentos e avaliá-los segundo indicadores ambientais é de suma importância, pois permite avaliar a condição destes nas bacias hidrográficas, bem como identificar áreas prioritárias para ações de recuperação e manejo a serem implantadas. Assim, o presente estudo traz uma classificação dos fragmentos florestais identificados na Bacia do Ribeirão Anhumas, CampinasSP, utilizando como indicadores as seguintes métricas de paisagem: tamanho, área nuclear e índice de circularidade. Para tanto, foi realizada uma Análise de Agrupamento com uso do software estatístico XSTAT, como forma de identificar as semelhanças entre os fragmentos, considerando os indicadores supracitados, e agrupá-los em classes. Uma correlação entre eles também foi desenvolvida a fim de identificar possíveis relações de interdependência. Constatou-se que a bacia estudada é altamente urbanizada, sobretudo na região do alto curso, local onde existem menos fragmentos, com tamanhos menores e em situação majoritária de isolamento. Embora, de forma geral, os fragmentos apresentem tamanho bom, há um considerável agravante: o índice de área nuclear é bem baixo, cerca de $25 \%$, o que implica que grande parte da área de cobertura ocupada pelos fragmentos encontra-se sujeita aos efeitos de borda. Além disso, pela análise de agrupamento, os fragmentos puderam ser agrupados em três classes, sendo o fator tamanho um dos mais determinantes. Identificou-se ainda a sub-bacia do baixo curso como a região menos urbanizada e com maiores fragmentos e maior potencial para a implantação de ações de manejo e recuperação dos fragmentos florestais como, por exemplo, corredores ecológicos.
\end{abstract}

Palavras-chave: Urbanização; Fragmentação florestal; Qualidade ambiental

\begin{abstract}
The urbanization in Campinas, São Paulo state, and the surrounding region had occurred in a fast and intensive way, causing big changes in the landscape and resulting in an expressive devastation of the forest areas and its natural vegetation cover. This circumstance had given rise to the forest fragmentation process. Therefore, mapping these fragments and evaluating them according to some environmental indicators is very important because it allows to evaluate the basin conditions and to identify the priority areas for the implementation of recovery and management actions. Thus, this work presents a classification of the forest fragments identified in 'Ribeirão Anhumas' watershed, Campinas, SP state, using as indicators the following landscape metrics: size, nuclear area and circularity index. Therefore, a Group Analysis was carried out using the statistical software XSTAT, as a way to identify the similarities between the fragments, considering the aforementioned indicators, and grouping them into classes. A correlation between them has also been developed in order to identify possible relationships of interdependence. It was found that this river basin is highly urbanized, where there are fewer fragments with smaller sizes and

\footnotetext{
Engenheira Ambiental e Sanitária, Mestranda em Sistemas de Infraestrutura Urbana, Centro de Ciências Exatas, Ambientais e de Tecnologia, Pontifícia Universidade Católica de Campinas, Rua Professor Dr. Euryclides de Jesus Zerbini, 1516, Parque Rural Fazenda Santa Cândida,

CEP 13087-571, Campinas (SP), Brasil. alessandra_ls@yahoo.com (ORCID: 0000-0001-6534-2122) Universidade Católica de Campinas, Rua Professor Dr. Euryclides de Jesus Zerbini, 1516, Parque Rural Fazenda Santa Cândida, CEP 13087-571, Campinas (SP), Brasil. regina.longo@puc-campinas.edu.br (ORCID: 0000-0002-2374-4649)/ marcius@puc-campinas.edu.br (ORCID: 0000-0003-4312-206X) Jesus Zerbini, 1516, Parque Rural Fazenda Santa Cândida, CEP 13087-571, Campinas (SP), Brasil. adrianobressane@ymail.com (ORCID: 0000-0002-4899-3983)
}

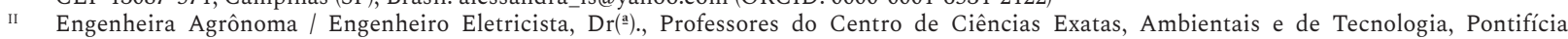

III Engenheiro Ambiental, Dr., Pós-doutorado em Sistemas Urbanos, Pontifícia Universidade Católica de Campinas, Rua Professor Dr. Euryclides de
\end{abstract}


in most cases isolated. Although the fragments were generally classified as good, there is a considerable aggravating factor for the environmental quality of these fragments: the nuclear area index was quite low, about $25 \%$, this implies that much of the area covered by fragments is subject to edge effects. Furthermore, through the cluster analyses the fragments had been grouped into three classes, where the size had been one of the most determinant factor. It was also identified the sub-basin of the low course as the less urbanized region, with larger fragments and greater potential for the implementation of management and recovery actions on the forest fragments, such as ecological corridors.

Keywords: Urbanization; Forest fragmentation; Cluster analyses

\section{Introdução}

As áreas de vegetação remanescente são denominadas por muitos autores como pertencentes aos sistemas de suporte à vida. Quando inseridas no contexto urbano, passam a integrar a chamada "infraestrutura verde", composta também por praças, bosques, parques, cinturões verdes e demais estruturas que, além de apresentarem funções estéticas e/ou de lazer, são significantes para o processo ecológico natural (BARGOS; MATIAS, 2011; CAMARGO et al., 2013; LONDE; CEZAR, 2014). Vale destacar que tal finalidade ecológica é essencialmente importante para as áreas de vegetação intraurbana, de modo que ao menos $70 \%$ da área total preservada deverão ser garantidos para este fim (BARGOS; MATIAS, 2011).

Ressalta-se, porém, que não existe ainda um consenso a respeito da definição destas áreas, o que pode levar, muitas vezes, à utilização errônea de terminologias como áreas verdes, verde urbano, cobertura vegetal, entre outras. Entretanto, o que vale destacar é que estes es paços exercem significativa influência sobre as condições de qualidade ambiental e de vida, dos ambientes e das populações residentes nos espaços urbanos (BARGOS; MATIAS, 2011; CAMARGO et al., 2013; LONDE; CEZAR, 2014). Atualmente, os conceitos de qualidade ambiental e qualidade de vida são completamente indissociáveis, principalmente no que diz respeito à mensuração da qualidade de vida urbana (NAHAS, 2009; STREIMIKIENE, 2015). Neste aspecto, as áreas com vegetação remanescente apresentam papel fundamental, pois através de suas funções sociais, estéticas e ecológicas contribuem para a amenização de impactos ambientais oriundos do processo de urbanização (HERZOG; ROSA, 2010). Apesar disto, dentro do contexto urbano, estas áreas encontram-se fragmentadas.

A fragmentação diz respeito à divisão em partes de uma dada unidade do ambiente e consiste, portanto, em separações físicas de um habitat natural anteriormente contínuo; o que provoca consideráveis alterações na paisagem natural, que tende a se tornar semelhante a um mosaico (CALEGARI et al., 2010; MASSOLI; STATELLA; SANTOS, 2016). Apesar do fenômeno de fragmentação existir naturalmente em um ambiente, este vem sendo altamente intensificado por ações antrópicas, principalmente em função da demanda por terra para produção de alimentos, construções e aumento da concentração de resíduos produzidos (COPQUE et al., 2011; DAMAME; LONGO; OLIVEIRA, 2019). Neste sentido, semelhantemente ao que ocorreu em grande parte do país, o município de Campinas, localizado no interior do Estado de São Paulo, sofreu com um rápido e desordenado processo de urbanização. Motivado pelos ciclos da cana-de-açúcar e do café, houve uma drástica redução na vegetação natural e fragmentação dos remanescentes em todo o município (CAMPINAS, 2017).

Além da redução na área original de habitat, estudos relatam que a fragmentação pode levar a extinções locais e alterações na composição e abundância de espécies, conduzindo à alteração ou até mesmo perda de processos naturais das comunidades (GARCIA et al., 2018). Modificações na dispersão de sementes por animais, na polinização, na predação de herbívoros e outros, podem ainda colocar em risco a manutenção das populações de espécies vegetais nativas nos remanescentes (CALEGARI et al., 2010). Outras consequências associadas à fragmentação florestal incluem: a alteração significativa da qualidade ambiental do meio por fatores como a redução da permeabilidade do solo e o surgimento de recorrentes alagamentos; os processos erosivos, com perda de qualidade de mananciais; alteração do microclima e impacto sobre as 
condições térmicas da cidade; entre outros (COPQUE et al., 2011; DAMAME et al., 2015).

Ademais, a transformação da estrutura florestal na borda destes fragmentos é também uma das principais consequências do processo de fragmentação (MASSOLI; STATELLA; SANTOS, 2016). Estudos apontam que há uma nítida diferença entre as áreas de borda e as regiões mais interiores dos fragmentos. Como exemplo cita-se a maior riqueza e diversidade de espécies nas áreas mais distantes da borda em comparação às áreas marginais que, por sua vez, apresentam menor diversidade e maior abundância de árvores de espécies pioneiras e regenerantes (OLIVEIRA et al., 2015).

De forma geral, a fragmentação provoca um efeito cascata sobre a estrutura florestal dos remanescentes, afetando árvores, insetos, espécies de vertebrados e invertebrados e perturbando gravemente os processos ecológicos mais básicos (TABARELLI et al., 2004 apud SAMPAIO, 2011). Neste processo, o efeito de borda constitui-se como uma das etapas iniciais da degradação florestal. A ocorrência e a intensidade destas alterações oriundas do efeito de borda sobre os fragmentos florestais estão condicionadas a uma série de fatores físicos, tais como quantidade, forma, tamanho e conectividade dos fragmentos. Compreender estes fatores e as implicações da fragmentação florestal nestes ecossistemas é, portanto, imprescindível no contexto de gestão ambiental e para o desenvolvimento de políticas públicas relacionadas ao uso e ocupação do solo (ANDERSSON et al., 2014; JESUS et al., 2015).

A quantificação do número de fragmentos presentes em determinada área de estudo, bem como o tamanho desses fragmentos, em associação a outros parâmetros de avaliação, como as métricas da paisagem, funcionam como excelentes indicadores, pois contribuem eficientemente para a identificação do grau de fragilidade destas áreas remanescentes frente aos efeitos de borda (CALEGARI et al., 2010; FENGLER et al., 2015). Como se percebe, a borda é um importante indicador da fragilidade dos fragmentos florestais, possibilitando identificar importantes informações a respeito da qualidade ambiental dessas áreas remanescentes. Desta forma, o presente estudo visa avaliar a fragilidade ambiental dos fragmentos florestais da Bacia do Ribeirão Anhumas, no município de Campinas, através dos indicadores "tamanho" e "formato" dos mesmos, promovendo correlação entre esses dois e identificando as similaridades dos fragmentos, de forma a facilitar a gestão ambiental dos mesmos.

\section{Metodologia}

A Bacia do Ribeirão Anhumas está localizada no interior do Estado de São Paulo sendo delimitada pelas coordenadas UTM, Zona 23 S, de 7.462 .827 a $7.482 .500 \mathrm{~N}$ e de 282.500 a 296.870 $\mathrm{L}$, e abrangendo uma área de aproximadamente $150 \mathrm{~km}^{2}$. A maior parte desta área está inserida no município de Campinas-SP, com uma pequena parcela no município de Paulínia-SP, conforme Figura 1.

Para a identificação dos remanescentes florestais, utilizaram-se como base os dados geoespaciais de uso e ocupação do solo da Bacia do Ribeirão Anhumas disponibilizados pela Secretaria Estadual de Meio Ambiente, que foram atualizados por checagens em campo no ano de 2017. O sistema de uso e ocupação do solo foi avaliado e reclassificado em cinco grandes grupos: (1) solo exposto, englobando solos sem cobertura vegetal para fins de plantios agrícolas, construção civil (áreas terraplanadas) e/ou abertas devido a processos erosivos; (2) áreas edificadas, abrangendo áreas residenciais, comerciais e de serviços, loteamentos, grandes equipamentos (indústrias, ETE, ETA, áreas institucionais, aterro, unidades de transporte), áreas de rodovias, área de lazer e desporto e edificações agrícolas; (3) áreas rurais, sendo elas as áreas de culturas (perenes, semiperenes e temporárias) e de pastagens; (4) áreas verdes, englobando áreas de mata, reflorestamento, espaços verdes urbanos, campo natural e áreas úmidas; e, por fim, (5) os recursos hídricos.

Por meio do software ArcGIS e com o auxílio de imagens orbitais obtidas no Google Earth PRO - Image (C 2016 DigitalGlobe delimitaram-se as áreas referentes à mata e reflorestamento, 
considerando também as áreas de vegetação remanescente presente na bacia do Ribeirão Anhumas e já denominadas como fragmentos florestais em outros trabalhos científicos.

Figura 1 - Localização da Bacia do Ribeirão Anhumas.

Figure 1 - Location of ‘Anhumas Ribeirão’ watershed.

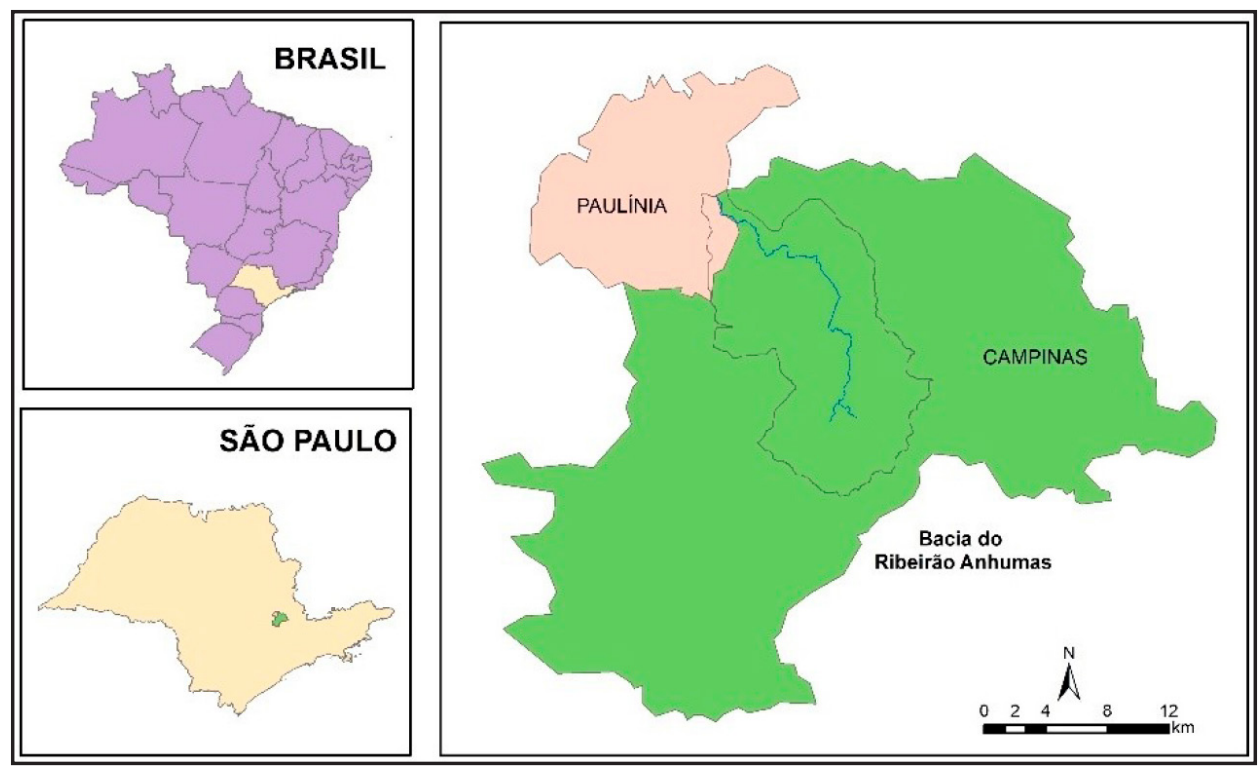

Fonte: Autores (2017)

Após a identificação e delimitação dos fragmentos florestais em SIG (Sistema de Informação Geográfica), calcularam-se área total, nuclear e perímetro referentes aos mesmos. A área nuclear refere-se à área central de um fragmento florestal desconsiderada faixa marginal, ou seja, aquela sujeita aos efeitos de borda. O valor desta faixa de efeito de borda varia na literatura; para este estudo foi utilizado o valor de $60 \mathrm{~m}$ adotado por Calegari et al. (2010). Desta forma, em software GIS delimitou-se um novo perímetro para cada um dos fragmentos florestais, subtraindo $60 \mathrm{~m}$ de bordas originalmente delimitadas.

Utilizando as informações de área e perímetro calculou-se o índice de circularidade (IC) e determinou-se a forma do fragmento. O índice de circularidade (IC) é um parâmetro bastante usual na literatura de avaliação de fragmentos florestais. O mesmo relaciona a área e o perímetro a fim de identificar o grau de proximidade do formato dos remanescentes com o de uma circunferência. A forma de uma circunferência é estabelecida como padrão teórico de comparação visto que à medida que o fragmento se aproxima de um formato circular a área limítrofe é minimizada em relação à área total, reduzindo assim os efeitos de borda como apresentado anteriormente (ETTO et al. , 2013; FENGLER et al., 2015; SILVÉRIO NETO et al., 2015). O cálculo do Índice de Circularidade (IC) foi realizado segundo a equação (I), apresentada por Etto et al. (2013):

$$
I C=\frac{(2 \cdot \sqrt{\pi \cdot A})}{L}
$$

em que: $\mathrm{A}$ = área do fragmento; $\mathrm{L}=$ perímetro do fragmento.

Por meio de tal relação foi gerado um valor adimensional que varia de zero a um, pelo qual foi possível avaliar quão próximo à forma circular o fragmento está. Valores mais próximos a 1 
indicam maior circularidade do remanescente; por outro lado, índices distantes de 1 representam fragmentos de formato mais alongado, nos quais maior é a proximidade entre a área central e as bordas e, por fim, maior a vulnerabilidade (FENGLER et al., 2015; SILVÉRIO NETO et al., 2015).

Após o cálculo dos índices, os mesmos foram classificados de acordo com Etto et al. (2013), segundo os quais fragmentos com índices inferiores a 0,65 foram identificados como fragmentos alongados; entre 0,65 e 0,85, como moderadamente alongados e com índices superiores a 0,85 , fragmentos com forma arredondada.

Em seguida, estes dados foram analisados conjuntamente para que fossem identificadas as correlações entre eles e as consequências implícitas. Para tanto utilizou-se o Coeficiente de Correlação de Pearson como medida de similaridade, de forma que quanto maior seu valor, maior o grau de associação entre duas variáveis. Para identificar possível semelhança entre os fragmentos, utilizou-se a análise Agglomerative Hierarchical Clustering (AHC) disponível no software XLSTATC. Adotou-se como medida de dissimilaridade a distância euclidiana, visto que, menores valores indicam objetos mais próximos (semelhantes) uns aos outros. Desta forma, os fragmentos foram agrupados com o uso de um dendrograma em classes de dissimilaridade.

\section{Resultados e discussão}

A classificação do uso e ocupação do solo da Bacia do Ribeirão Anhumas resultou na definição de cinco principais classes de uso: solo exposto $(5,07 \%)$, recursos hídricos $(1,00 \%)$, áreas verdes $(16,74 \%)$, áreas rurais $(27,39 \%)$, áreas edificadas $(49,80 \%)$, distribuídas em uma área total de $156,514 \mathrm{~km}^{2}$. De acordo com a Figura 2 foi possível observar o alto grau de urbanização, especialmente na região do alto curso do Ribeirão Anhumas; onde $66,6 \%$ da área é ocupada por áreas já edificadas. Este índice é de $48,3 \%$ no médio curso e $32,4 \%$ no baixo curso. Uma das implicações desta alta urbanização verificada à montante da bacia é o acúmulo de carga poluidora, como resíduos sólidos, efluentes domésticos e industriais, e o excesso de água das inundações produzidos no alto curso, acumulados ao longo da bacia e levados para a região mais baixa da mesma (SOUZA; LAGANÁ; CHAVES, 2012).

Desse modo, observou-se que a ocupação urbana torna o ambiente cada vez mais artificial. Como destacam Chaves e Santos (2009), as alterações de uso e ocupação no solo, associadas ao processo de urbanização, tais como o parcelamento do solo, a construções de edificações e o aumento da densidade viária são alguns dos principais fatores associados ao aumento da fragmentação das paisagens naturais.

O efeito causado pela urbanização sobre as comunidades florestais é uma questão importante para os gestores ambientais, tanto para o uso da terra como para a conservação da natureza. Uma das consequências diretas da fragmentação florestal é justamente a formação de borda na floresta original, na qual espécies de flora e fauna, anteriormente adaptadas ao habitat do interior da floresta, passam a ser expostas a fatores abióticos como altos índices de temperatura, luminosidade, vento e baixa umidade. O reflexo dessa exposição é a morte dos indivíduos que estão na borda; já com relação à flora, existe o maior risco de invasão por espécies vegetais de características de habitat mais aberto (HOLANDA et al., 2010).

Apesar de as áreas verdes ocuparem um percentual de $12,1 \%, 14,7 \%$ e $14,6 \%$ nas subbacias do alto, médio e baixo curso, respectivamente, identificou-se que a área abrangida por fragmentos de vegetação florestal remanescente são poucas. Ao desconsiderar os espaços verdes urbanos, as áreas de campo natural (ausência de vegetação arbórea) e áreas úmidas destituídas de vegetação arbórea próximas aos corpos d'água tem-se uma área de 1002,1 ha ocupada por 128 fragmentos florestais, correspondente a apenas $6,40 \%$ da área total da bacia.

A sub-bacia do baixo curso, como maior região da bacia e também a de menor urbanização, foi a que apresentou maior número e área de fragmentos, sendo 652,23 ha; em seguida temse a sub-bacia do médio curso com 216,61 ha de área de fragmentos e, por fim, o alto curso com 133,26 ha. O presente estudo considerou tanto as matas estabelecidas quanto as áreas de 
reflorestamento em geral. Segundo um estudo de Etto et al. (2013) na sub-bacia do Ribeirão das Pedras, Campinas, o aumento ao longo dos últimos anos na quantidade de áreas verdes se deu especialmente em função do aumento de áreas de reflorestamento.

Figura 2 - Classes de uso e ocupação do solo da Bacia do Ribeirão Anhumas.

Figure 2 - Land use and occupation classes on 'Anhumas' River Watershed.

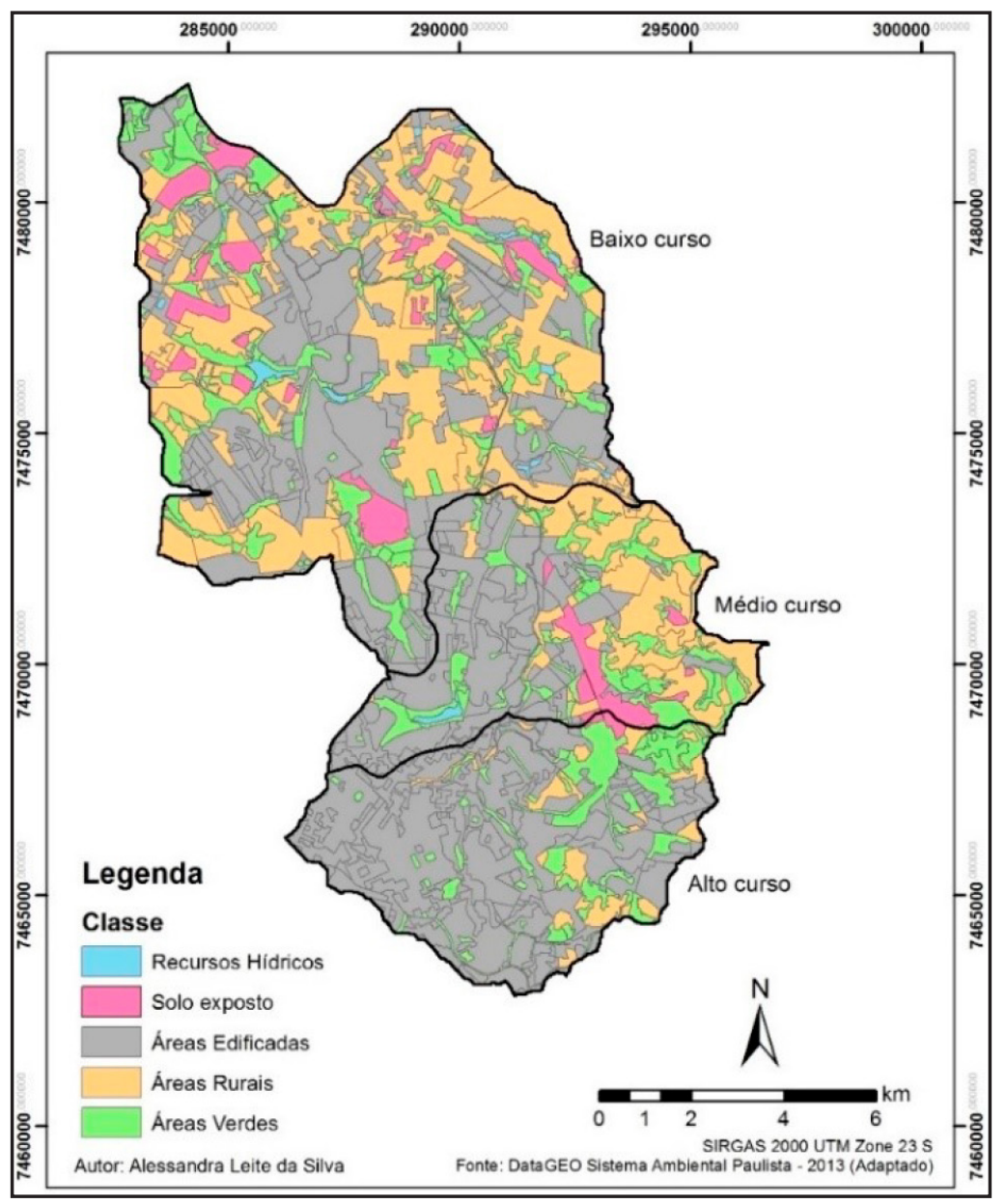

Fonte: Autores (2017)

A classificação com relação ao tamanho destes fragmentos está apresentada na Tabela 1 e Figura 3a. Mais de $87 \%$ dos 128 fragmentos mapeados apresentaram área entre 1 e 20 ha (SILVA et al., 2017), podendo ser agrupados nas classes de tamanho "médio" e "bom". Constatouse ainda que grande parte destes remanescentes maiores está localizada no baixo curso; não apenas pelo fato desta ser a maior sub-bacia do Ribeirão Anhumas, mas também por tratar-se da região menos urbanizada e, portanto, com áreas um pouco mais conservadas. Apenas nove fragmentos presentes na bacia apresentaram área superior a 20 ha, dos quais: cinco se encontram no baixo curso e quatro no médio curso, sendo que um destes apresenta uma pequena parcela de área no alto curso. Ao contrário do constatado por Pirovani et al. (2014) na Bacia do Rio Itapemirim, Espírito Santo, não foram identificados muitos fragmentos florestais com tamanho muito pequeno, ou seja, inferior a 0,5 ha; existe apenas um fragmento nesta classe de tamanho, localizado no alto curso.

Com relação à área nuclear, ou seja, a área central do fragmento florestal, a análise quantitativa mostrou que dos 1002,10 ha de área total de fragmentos, apenas 258,94 ha consistem 
em área nuclear, representando $25,8 \%$ da área total. Isto implica que os 743,16 ha de área restante $(74,2 \%)$ são áreas de borda. Pela análise da Figura 3b identificou-se ainda que em muitos fragmentos, especialmente naqueles de menor área, não existe área nuclear; constatação também realizada por Sampaio (2011) em trechos de um fragmento localizado no município de Lençóis Paulista, Estado de São Paulo. Esta condição evidencia que toda a área do fragmento consiste em área de borda, indicando que o fragmento se encontra vulnerável e altamente suscetível aos efeitos de borda. Um fragmento pode até apresentar área suficiente para abrigar determinadas espécies, mas não as suporta devido à ausência de área nuclear suficiente (MASSOLI; STATELLA; SANTOS, 2016). Para estes fragmentos, que totalizam 108,38 ha de área, existe inclusive a possibilidade de que sejam completamente eliminados da paisagem, conforme enfatizam Greggio, Pissarra e Rodrigues (2009).

Tabela 1 - Tamanho (área total) dos fragmentos florestais.

Table 1 - Size (total area) of forest fragments.

\begin{tabular}{lcccccc}
\hline & & \multicolumn{5}{c}{ No fragmentos } \\
\cline { 3 - 7 } Área $($ ha) & Classificação & $\begin{array}{c}\text { Alto } \\
\text { curso }\end{array}$ & $\begin{array}{c}\text { Médio } \\
\text { curso }\end{array}$ & $\begin{array}{c}\text { Baixo } \\
\text { curso }\end{array}$ & Total & $\begin{array}{c}\text { Área total } \\
\text { (ha) }\end{array}$ \\
\hline$<\mathbf{0 , 5 0}$ & Muito pequeno & 1 & - & - & 1 & 0,36 \\
$\mathbf{0 , 5 0}-\mathbf{1 , 0 0}$ & Pequeno & - & 1 & 5 & 6 & 4,43 \\
$\mathbf{1 , 0 0}-\mathbf{5 , 0 0}$ & Médio & 12 & 8 & 39 & 59 & 169,04 \\
$\mathbf{5 , 0 0}-\mathbf{2 0 , 0 0}$ & Bom & 8 & 11 & 4 & 53 & 499,05 \\
$>\mathbf{2 0 , 0 0}$ & Adequado & - & 4 & 5 & 9 & 329,23 \\
\hline & Total & 21 & 24 & 83 & 128 & 1002,11 \\
\hline
\end{tabular}

Estudos demonstram que quanto menor o fragmento maior será a intensidade do efeito de borda. O tamanho do fragmento é, portanto, um fator decisivo na dinâmica da população, visto que os efeitos de borda podem contribuir ainda mais para a redução da área do fragmento (CALEGARI et al., 2010). Além disso, o tamanho de um fragmento pode ter efeito direto na sobrevivência das populações das espécies (MASSOLI; STATELLA; SANTOS, 2016). Quanto menor o fragmento, maior a influência dos fatores externos sobre ele, de forma que, reduções significativas de área nos remanescentes florestais, podem afetar sua estrutura e dinâmica biológica, criando condições desfavoráveis para inúmeras espécies e prejudicando sua autossustentabilidade (JESUS et al., 2015).

Um dos fatores determinantes da área nuclear é o tamanho total do fragmento. De maneira geral, deduz-se que fragmentos com maior área total apresentarão também maior área nuclear, indicando, desta forma, maior preservação do interior do fragmento. Esta interação pôde ser percebida pela análise da Figura 4, pela qual se observou a relação diretamente proporcional entre a área nuclear e área total dos fragmentos florestais. O coeficiente de correlação de Pearson, neste caso, foi de 0,96, o que indica forte correlação. Por tratar-se de um valor positivo esta relação é diretamente proporcional. Além disso, a associação entre tamanhos pequenos e formatos irregulares é uma das principais causas para o decréscimo de área nuclear nos fragmentos florestais (FERNANDES; FERNANDES, 2017).

Ademais, Silva et al. (2015) destacam que fragmentos com área inferior a 1 ha apresentam uma alta relação entre perímetro de borda e área e são, portanto, os mais susceptíveis a essas interferências externas. Sendo assim, existe uma associação direta entre a relação perímetro/área com a área nuclear do fragmento. Quanto maior o valor da área central, menor será a densidade 
de bordas, e menos susceptíveis aos efeitos de bordas tal fragmento estará (SILVA; MELO, 2014). Neste sentido, o índice de circularidade é outro indicador muito relevante para estudo da estrutura de fragmentos florestais, pois, além de promover a relação entre perímetro e área dos fragmentos, permite avaliar o nível de proteção no interior dos fragmentos frente ao efeito de borda (ETTO et al., 2013).

Figura 3 - (a) Classificação dos fragmentos florestais na Bacia do Ribeirão Anhumas quanto ao tamanho e (b) diferenças entre área nuclear e área de borda.

Figure 3 - (a) Classification of forest fragments in the Anhumas River Watershed and (b) the differences between nuclear area and border area.

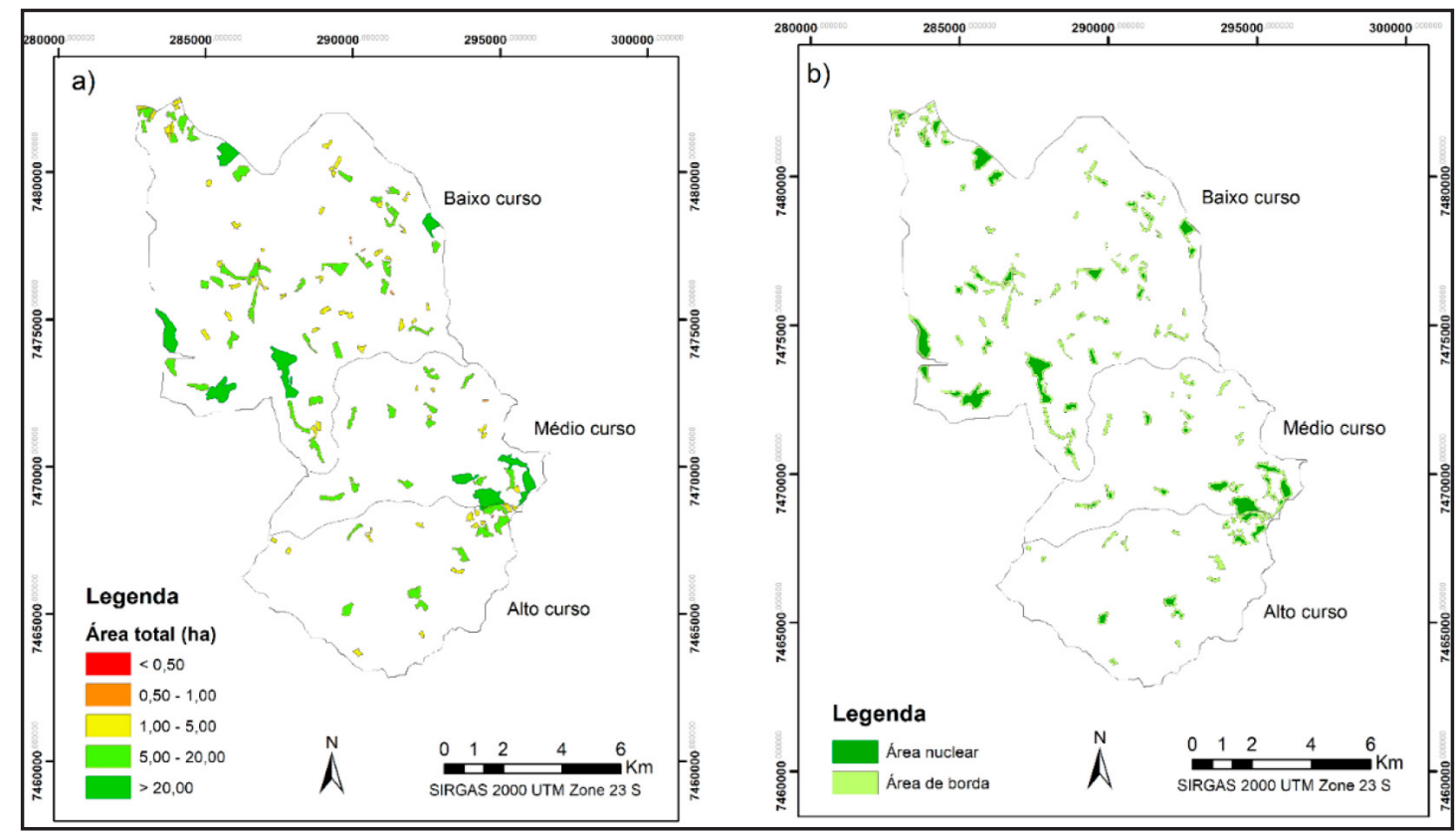

Fonte: Autores (2017)

Figura 4 - Correlação entre área total e área nuclear.

Figure 4 - Correlation between total area and nuclear area.

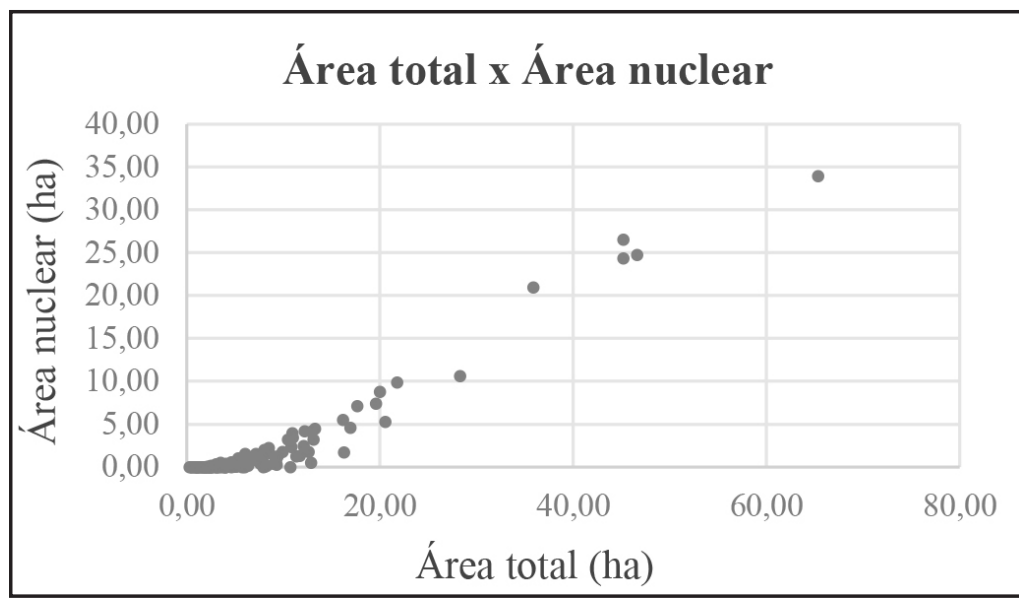

Fonte: Autores (2017) 
Quanto mais circular for um fragmento mais compacto ele é e menor sua vulnerabilidade às atividades de uso do solo do entorno. Isto porque menor será sua razão borda/interior, mantendo a porção central do fragmento equidistante da borda e diminuindo a vulnerabilidade da vegetação interior ao efeito de borda (FENGLER et al., 2015). Assim, a forma do fragmento florestal pode aumentar a interação entre o remanescente natural e a área antropizada no seu entorno, influenciando os processos ecológicos locais e atuando principalmente sobre o efeito de borda e sua área de abrangência (PIROVANI et al., 2014; MASSOLI; STATELLA; SANTOS, 2016). A Figura 5 apresenta a distribuição espacial e a classificação dos fragmentos da Bacia do Ribeirão Anhumas quanto ao índice de circularidade.

Figura 5 - Índice de Circularidade (IC).

Figure 5 - Circularity Index.

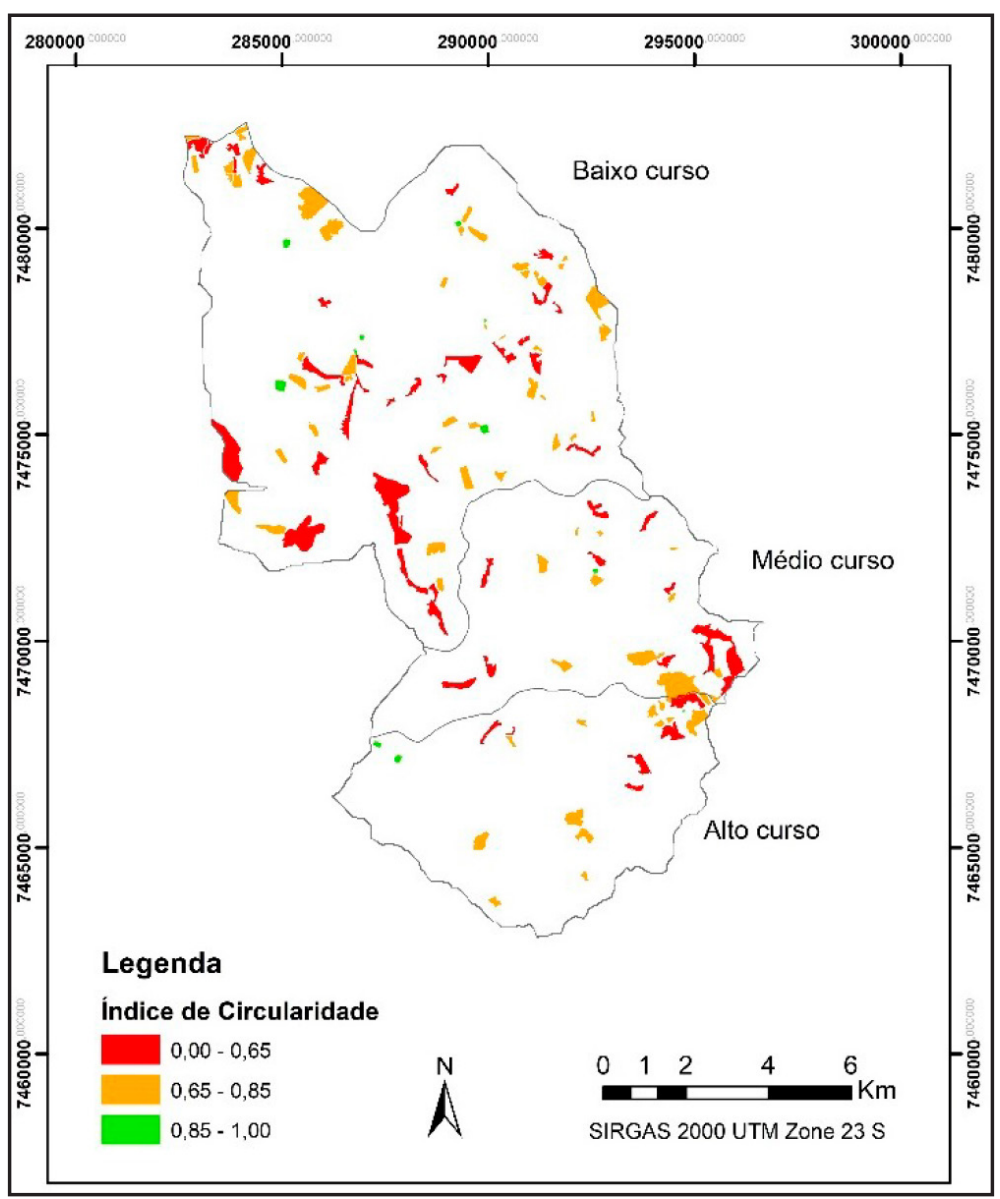

Fonte: Autores (2017)

Identificou-se que mais de 50\% dos fragmentos apresentam índice entre 0,65 e 0,85, permitindo classificá-los como moderadamente alongados, 37,5\% foram classificados como alongados e apenas $8,6 \%$ com formatos adequadamente arredondados (Tabela 2). Fengler et al. (2015), ao avaliar este mesmo índice na bacia hidrográfica do Rio Jundiaí-Mirim-SP verificaram resultados semelhantes, em que $36,9 \%$ e $29,8 \%$ dos fragmentos apresentaram índices de 0,400,60 e 0,60-0,80, respectivamente. A similaridade destes resultados pode indicar não apenas uma situação da bacia do Ribeirão Anhumas, mas revelar uma condição atual dos fragmentos das bacias hidrográficas de Campinas e região. 
Tabela 2 - Índice de Circularidade (IC).

Table 2 - Circularity Index.

\begin{tabular}{lccccccc}
\hline \multirow{2}{*}{ IC } & \multirow{2}{*}{ Forma } & \multicolumn{3}{c}{ No fragmentos } & \multirow{2}{*}{ Total } & \% \\
\cline { 3 - 5 } & & Alto & Médio & Baixo & & 48 & 37,5 \\
\hline$<\mathbf{0 , 6 5}$ & Alongada & 6 & 11 & 31 & & 45 & 53,9 \\
$\mathbf{0 , 6 5}-\mathbf{0 , 8 5}$ & Moderadamente alongada & 13 & 11 & 45 & 69 & 8,6 \\
$>\mathbf{0 , 8 5}$ & Médio & 3 & 1 & 7 & 11 & 100 \\
\hline & Total & 22 & 23 & 83 & 128 & \\
\hline
\end{tabular}

Constatou-se, porém, pela análise do gráfico apresentado na Figura 6, que, na bacia do Ribeirão Anhumas, os maiores índices de circularidade provêm de fragmentos com menores áreas, permitindo realizar duas constatações importantes.A primeira é que os fragmentos, em sua maioria, caracterizam-se por um tamanho de pequeno a médio, tal como já apresentado anteriormente, o que aumenta sua vulnerabilidade e intensifica o efeito de borda. A segunda é que os poucos fragmentos de maior área, que poderiam ser mais significativos à qualidade ambiental na região, apresentam baixos índices de circularidade e, portanto, formatos alongados. Condições como esta, tal como destaca Sampaio (2011), tornam os fragmentos altamente sujeitos aos efeitos de borda, que passa a atuar em praticamente toda a extensão da área de vegetação remanescente, podendo comprometer sua sustentabilidade em longo prazo.

Não obstante, os maiores índices de circularidade estiveram associados a fragmentos que não apenas possuem reduzida área total, como também possuem área nuclear irrisória ou nula. Esta observação é muito importante e deve ser considerada no diagnóstico destes fragmentos, visto que a análise isolada do índice de circularidade poderia ocultar o alto grau de vulnerabilidade e susceptibilidade nos quais se encontram estes fragmentos, principalmente devido a outros fatores, como a ausência de área nuclear, por exemplo. Além disso, Calegari et al. (2010) destacam que apesar de, em geral, os fragmentos de maior área total apresentarem maiores áreas nucleares, quando se verifica grande diferença de índice de forma, fragmentos de mesmo tamanho total podem apresentar grande diferença de área nuclear.

Figura 6 - Relação entre área de borda, área nuclear e índice de circularidade (IC).

Figure 6 -Relationship between border area, nuclear area and circularity index (CI).

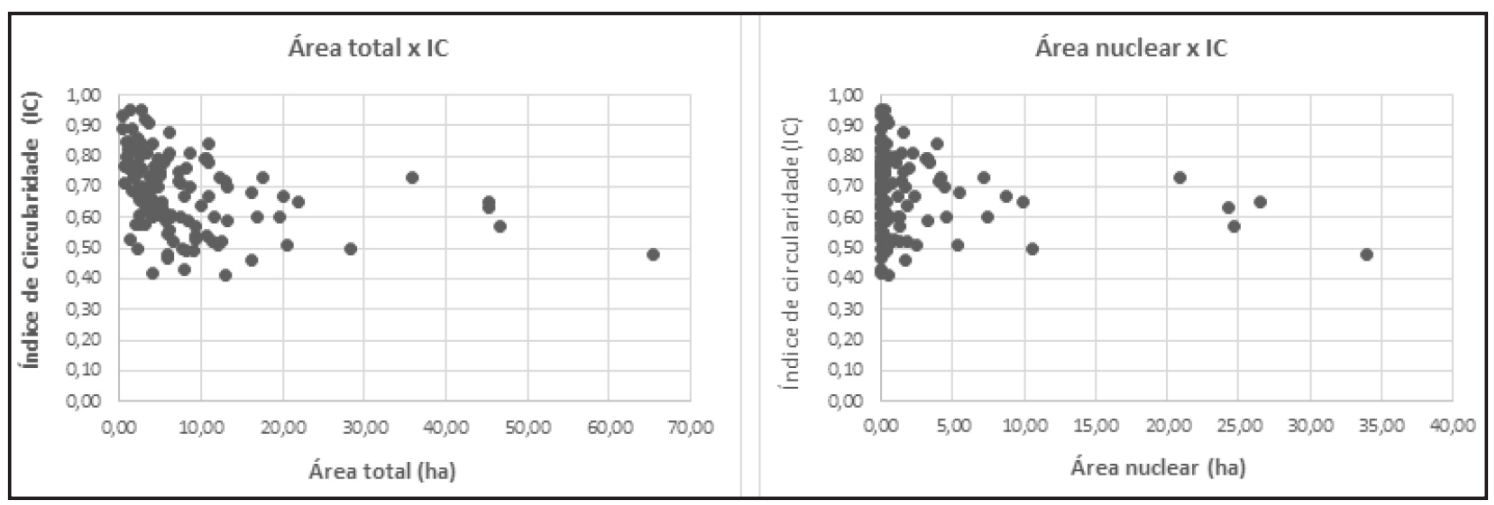

Fonte: Autores (2017) 
É importante considerar ainda que, pelo fato de encontrarem-se fragmentadas e isoladas, estas áreas passam a sofrer mais intensamente os efeitos oriundos do ambiente externo. Entretanto, a intensidade deste processo denominado como efeito de borda, está ainda sujeita a outros fatores; por se tratar de um fenômeno que atua principalmente nas áreas limítrofes dos fragmentos, o tipo de uso e ocupação no entorno destes fragmentos é influente sobre o grau de fragilização dos mesmos e deve também ser considerado (JESUS et al., 2015).

A Tabela 3 apresenta as análises estatísticas dos dados citados anteriormente realizadas por meio do software XLSTAT. Foi possível observar amplitude muito alta dos fatores área e área nuclear, sendo estes os indicadores que apresentaram maiores desvios padrões. O desvio padrão é uma importante medida estatística, pois indica uma faixa de normalidade ao redor da média na qual há a maior incidência das observações, em geral 68,26\% do total (FEIJOO, 2010).

Considerando estes dados e os dados individuais de cada fragmento, a análise de agrupamento realizada através do método Agglomerative Hierarchical Clustering (AHC) permitiu avaliar o grau de dissimilaridade entre os mesmos, classificando-os conforme apresentado na Figura 7. O eixo horizontal apresenta os grupos formados enquanto o eixo vertical indica as distâncias entre estes grupos. Quanto maior a distância, menor a semelhança entre os elementos. Ainda com base na distância euclidiana, a linha tracejada paralelamente ao eixo x, denominada como linha fenon permitiu interceptar todos os ramos gerados e classificar os fragmentos em 3 grupos específicos, denominados como Classes 1, 2 e 3 . A Classe 1 é a que abrange o maior número de fragmentos, são 78 nesta classe (identificadas na Figura 7 em azul), 45 na Classe 3 (verde) e apenas 5 na Classe 2 (vermelho).

Tabela 3 - Resumo das estatísticas obtidas no software XLSTAT.

Table 3 - Summary of statistics obtained through the XLSTAT software.

\begin{tabular}{lccccc}
\hline \multicolumn{1}{c}{ Variáveis } & Observações & Mínimo & Máximo & Média & Desvio padrão \\
\hline Área $($ ha) & 128 & 0,360 & 65,380 & 7,829 & 9,730 \\
IC & 128 & 0,410 & 0,950 & 0,687 & 0,125 \\
Forma $^{*}$ & 128 & 1,000 & 3,000 & 1,711 & 0,617 \\
Área nuclear \% $^{128}$ & 0,000 & 58,660 & 10,516 & 14,794 \\
\hline
\end{tabular}

* Em que 1,000 foi adotado para representar forma alongada; 2,000 moderadamente alongada e 3,000 arredondada.

Constatou-se ainda que a área e a área nuclear foram fatores determinantes para a classificaçãodos fragmentos, sendo possível identificar que os fragmentos da Classe 2 apresentaram predominantemente as maiores áreas total e nuclear. A Tabela 4 apresenta os resultados desta análise estatística por classe. Como apresentado na Figura 8, identificou-se que esta classificação não tem distribuição es pacial preferencial. Apesar disto, nota-se a predominância dos fragmentos da Classe 2 na sub-bacia do baixo curso; esta classe é praticamente ausente no médio e alto curso. Por sua vez, os fragmentos das Classes 1 e 3 são encontrados nas três sub-bacias e consistem em fragmentos com tamanho um pouco menores, o que reforça a consideração de que a área foi um fator determinante para a classificação. Esta análise e classificação permitem auxiliar a gestão ambiental na bacia do Ribeirão Anhumas, identificando as medidas de manejo mais adequadas para cada classe de fragmentos; considerando a similaridade entre eles, as ações direcionadas proporcionarão melhores resultados. 
Figura 7 - Dendrograma resultante da análise de agrupamento dos diferentes fragmentos florestais, utilizando a distância euclidiana como coeficiente de dissimilaridade e o algoritmo Ward como método de agrupamento quanto aos atributos geoespaciais.

Figure 7 - Dendogram resulting from cluster analysis of different forest fragments, using Euclidean distance as a coefficient of dissimilarity and the Ward algorithm as a grouping method for geospatial attributes.

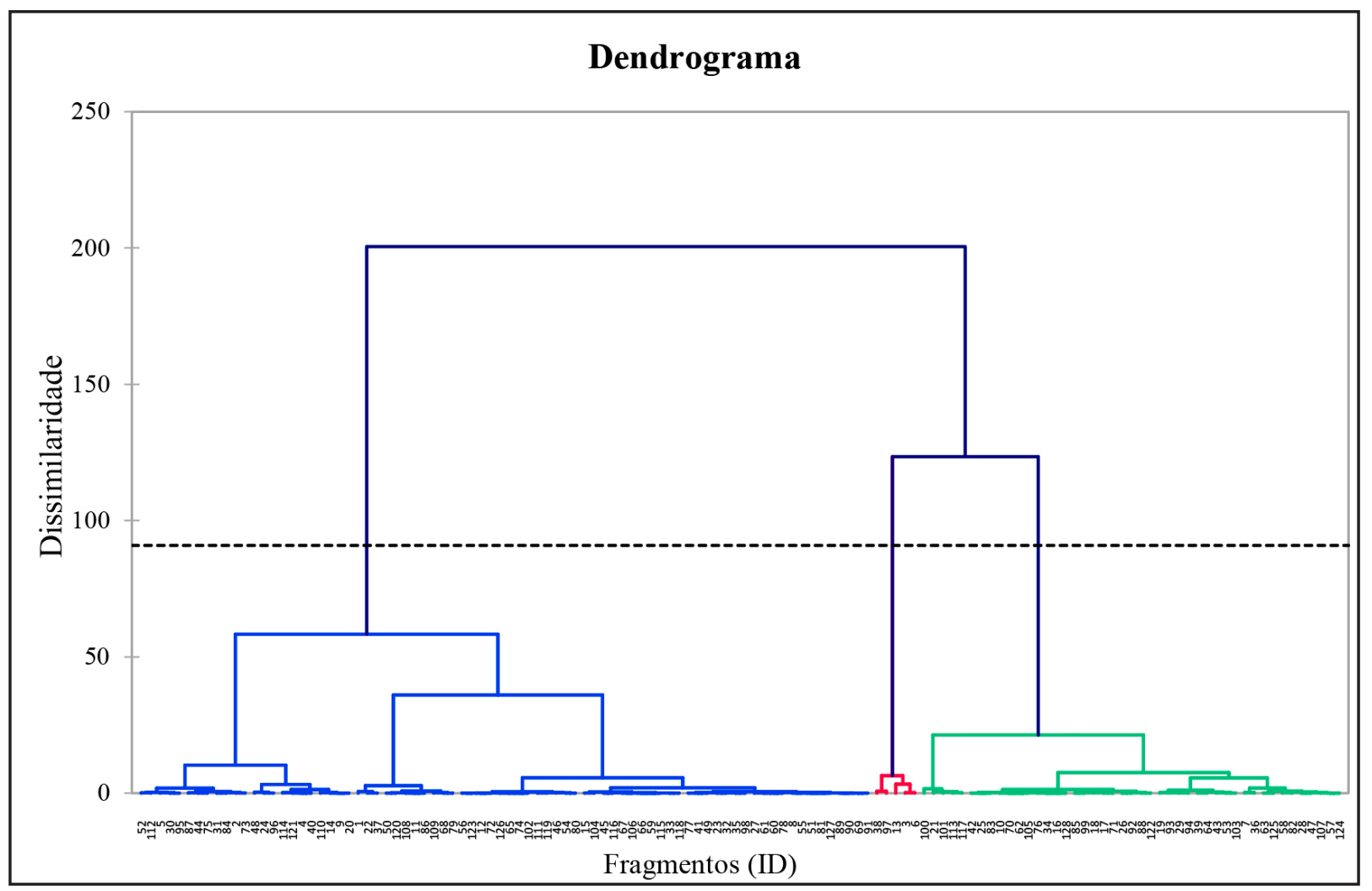

Fonte: Autores (2017)

Tabela 4 - Resultados por classe da Análise de Agrupamento.

Table 4 - Results by Class of Grouping Analysis.

\begin{tabular}{|c|c|c|c|c|}
\hline & Classe & 1 & 2 & 3 \\
\hline & № fragmentos & 78 & 5 & 45 \\
\hline \multirow{8}{*}{ } & Área (ha) & 4,998 & 47,692 & 8,308 \\
\hline & Índice de circularidade & 0,768 & 0,612 & 0,553 \\
\hline & Forma & 2,141 & 1,400 & 1,000 \\
\hline & Área nuclear (\%) & 9,470 & 55,122 & 7,373 \\
\hline & Variação dentro da classe & 187,997 & 125,966 & 131,634 \\
\hline & Distância mínima ao centroide & 1,318 & 2,425 & 1,805 \\
\hline & Distância média ao centroide & 11,308 & 7,940 & 9,076 \\
\hline & Distância máxima ao centroide & 39,560 & 17,982 & 36,101 \\
\hline
\end{tabular}


Figura 8 - Distribuição espacial dos fragmentos segundo s classificação resultante da Análise de Agrupamento.

Figure 8 - Spatial distribution of fragments according to Grouping Analysis classification.

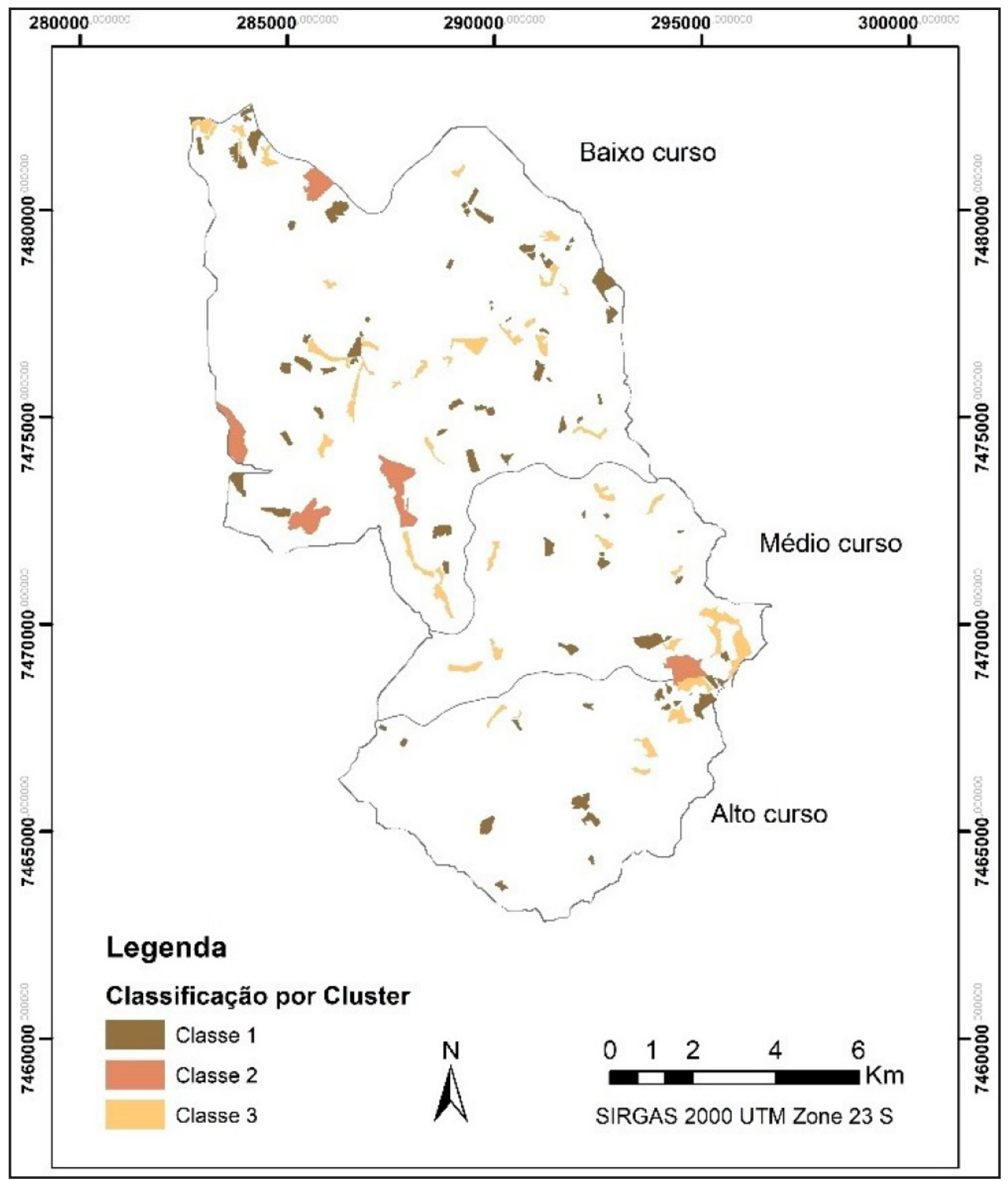

Fonte: Autores (2017)

\section{Conclusão}

De acordo com os indicadores ambientais analisados conclui-se que:

a) A Bacia Hidrográfica do Ribeirão Anhumas apresenta alto grau de urbanização, especialmente na região do alto curso, onde está localizada a região central do município de Campinas, estendendo-se também para o médio e baixo curso.

b) A vegetação florestal remanescente da bacia do Ribeirão Anhumas encontra-se fragmentada. A maioria dos fragmentos florestais observados apresentam tamanho considerado 
de médio a bom, variando de 1 ha a 20 ha, aproximadamente, estando localizados principalmente no baixo curso do Anhumas, que ainda é a região menos urbanizada da bacia.

c) Apesar de apresentarem tamanhos considerados como bons, a correlação entre tamanho (área total) e índice de circularidade (IC) indicou que os fragmentos analisados apresentam baixos índices de circularidade e pouca representatividade de área nuclear, estando, dessa forma, sujeitos ao efeito de borda, o que pode comprometer a estabilidade e a autossustentabilidade dos fragmentos florestais da bacia;

d) A Análise de Agrupamento mostrou-se um instrumento bastante útil para a classificação dos fragmentos quanto às suas semelhanças considerando os indicadores analisados, visto que permitiu o agrupamento destes em classes precisas e representativas;

e) A sub-bacia do baixo curso é a região na qual há maior predominância dos fragmentos de Classe 2, caracterizados principalmente por sua maior área total, o que indica um alto potencial desta região para implantação de ações de manejo florestal voltadas à recuperação de vegetação, além de propostas de conectividade, por meio de corredores ecológicos.

\section{Agradecimentos}

À FAPESP, pela bolsa de iniciação científica (Processo nº 2016/19727-6) concedida à primeira autora, à Coordenação de Aperfeiçoamento de Pessoal de Nível Superior (CAPES) pela bolsa de pós-doutorado concedida ao terceiro autor e à Pontifícia Universidade Católica de Campinas (PUC Campinas).

\section{Referências}

ANDERSSON, E. et al. Reconnecting cities to the biosphere: stewardship of green infrastructure and urban ecosystem services. AMBIO, Stockholm, v. 43, n. 4, p. 445-453, 2014.

BARGOS, D. C.; MATIAS, L. F. Áreas verdes urbanas: um estudo de revisão e proposta conceitual. Revista da Sociedade Brasileira de Arborização Urbana, Piracicaba, v. 6, n. 3, p. 172-188, 2011.

CALEGARI, L. et al. Análise da dinâmica de fragmentos florestais no município de Carandaí, MG, para fins de restauração florestal. Revista Árvore, Viçosa, MG, v. 34, n. 5, p. 871-880, out. 2010.

CAMARGO, M. et al. A sustentabilidade urbana analisada através do estudo de implantação de corredores verdes em dois logradouros da cidade de Cruz Alta/RS. Revista Gedecon, Cruz Alta, v. 1, n. 1, p. 127-135, 2013.

CAMPINAS. Prefeitura Municipal de Campinas. Plano Diretor Estratégico. Campinas: Secretaria de Planejamento e Desenvolvimento Urbano, 2017.

CHAVES, H. M. L.; SANTOS, L.B. Ocupação do solo, fragmentação da paisagem e qualidade da água em uma pequena bacia hidrográfica. Revista Brasileira de Engenharia Agrícola e Ambiental, Campina Grande, v. 13, p. 922-930, dez. 2009.

COPQUE, A. C. S. M. et al. Expansão urbana e redução de áreas verdes na localidade do Cabula VI Região do miolo da cidade do Salvador, Bahia. In: SIMPÓSIO BRASILEIRO DE SENSORIAMENTO REMOTO, 15., 2011, Curitiba. Anais [...]. São José dos Campos: SBSR, 2011. p. 0706-0713.

DAMAME, D. B. et al. Variation of the anthropic vulnerability in Ribeirão das Pedras watershed in Campinas/SP - Brazil. Geophysical Research Abstracts, Vienna, v. 17, p. 577, 2015.

DAMAME, D. B.; LONGO, R. M.; OLIVEIRA, E. D. Impactos ambientais pelo uso e ocupação do solo em sub bacias hidrográficas de Campinas, São Paulo, Brasil. Acta Brasiliensis, Campina Grande, v. 3, n. 1, p. 1-7, 2019. 
ETTO, T. L. et al. Ecologia da paisagem de remanescentes florestais na bacia hidrográfica do Ribeirão das Pedras - Campinas -SP. Revista Árvore, Viçosa, MG, v. 37, n. 6, p. 1063-1071, dez. 2013.

FEIJOO, A. M. L. C. Medidas de dispersão. In: A PESQUISA e a estatística na psicologia e na educação. Rio de Janeiro: Centro Edelstein de Pesquisas Sociais, 2010. p. 23-27.

FENGLER, F. H. et al. Environmental quality of forest fragments in Jundiaí-Mirim river basin between 1972 and 2013. Revista Brasileira de Engenharia Agrícola e Ambiental, Campina Grande, v. 19, n. 4, p. 402-408, abr. 2015.

FERNANDES, M. M.; FERNANDES; M. R. M. Análise espacial da fragmentação florestal da Bacia do Rio Ubá - RJ. Ciência Florestal, Santa Maria, v. 27, n. 4, p. 1429-1439, out./dez. 2017.

GARCIA, J. M. et al. Uso de fotografias hemisféricas para avaliação da qualidade ambiental na Mata de Santa Genebra, Campinas-SP, Brasil. Ciência Florestal, Santa Maria, v. 28, n. 1, p.175190, jan./mar. 2018.

GREgGiO, T. C.; PISSARRA, T. C. T.; RODRIGUES, F. M. Avaliação dos fragmentos florestais do município de Jaboticabal-SP. Revista Árvore, Viçosa, MG, v. 33, n. 1, p. 117-124, fev. 2009.

HERZOG, C. P.; ROSA, L. Z. Infraestrutura verde: sustentabilidade e resiliência para a paisagem urbana. Revista LABVERDE, São Paulo, n. 1, p. 92-115, set. 2010.

HOLANDA, A. C. et al. Estrutura de espécies arbóreas sob efeitos de borda em um fragmento de floresta estacional semidecidual em Pernambuco, Viçosa, MG, Revista Árvore, Viçosa, MG, v. 34, n. 1, 2010.

JESUS, E. N. et al. Estrutura dos fragmentos florestais da Bacia Hidrográfica do Rio Poxim-SE, como subsídio à restauração ecológica. Revista Árvore, Viçosa, MG, v. 39, n. 3, p. 467-474, 2015.

LONDE, P. R.; CEZAR, M. P. A influência das áreas verdes na qualidade de vida urbana. Hygeia, Uberlândia, v. 10, n. 18, p. 264-272, 2014.

MASSOLI, J. V.; STATELlA, T.; SANTOS, V. S. Estimativa da fragmentação florestal na microbacia Sepotubinha, Nova Marilândia - MT, entre os anos de 1990 a 2014. Caminhos de Geografia, [s. 1.], v. 17, n. 60, p. 480-60, 2016.

NAHAS, M. I. P. Indicadores Intra-urbanos como instrumento de gestão da qualidade de vida urbana em grandes cidades: uma discussão teórico-metodológica. In: VITTE, A. C.; KEINERT, T. M. M. (org.). Qualidade de vida, planejamento e gestão urbana: discussões teóricometodológicas. Rio de Janeiro: Bertrand Brasil, 2009. 312 p.

OLIVEIRA, L. S. C. et al. Edge effect in Atlantic Forest Remnants in the watershed of the river Tapacurá, Perbambuco. Cerne, Lavras, v. 21, n. 2, p. 169-174, 2015.

PIROVANI, D. B. et al. Análise espacial de fragmentos florestais na Bacia do Rio Itapemirim, ES. Revista Árvore, Viçosa, MG, v. 38, n. 2, p. 271-281, abr. 2014.

SAMPAIO, R. C. N. Efeito de borda em um fragmento de floresta estacional semidecidual no interior do Estado de São Paulo. 2011. Dissertação (Mestrado em Ciência Florestal) Universidade Estadual Paulista, Faculdade de Ciências Agronômicas, São Paulo, 2011.

SILVA, A. L. et al. Fragmentação e análise espacial dos remanescentes florestais na Bacia Hidrográfica do Ribeirão Anhumas, Campinas-SP. In: REUNIÃO ANUAL DA SBPC, 69., 2017, Belo Horizonte. Anais [...]. Belo Horizonte: SBPC, 2017.

SILVA, K. G. et al. Análise da dinâmica espaço-temporal dos fragmentos florestais da sub-bacia hidrográfica do Rio Alegre, ES. Cerne, Lavras, v. 21, n. 2, p. 311-318, jun. 2015.

SILVA, M. S. F.; MELO, R. Padrões espaciais de fragmentação florestal na FLONA do Ibura - 
Sergipe. Revista Mercator, Fortaleza, v. 13, n. 3, p. 121-137, 2014.

SILVÉRIO NETO, R. S. et al. Caracterização da cobertura florestal de Unidades de Conservação da Mata Atlântica. Floresta e Ambiente, Seropédica, v. 22, n. 1, p. 32-41, 2015.

SOUZA, L. S.; LAGANÁ, M. V.; CHAVES, M. A. R. Estudo das enchentes nas proximidades do Tilli Center, às margens do Ribeirão das Pedras, Campinas, SP. Revista Ciências do Ambiente On-Line, Campinas, v. 8, n. 2, p. 21-27, out. 2012.

STREIMIKIENE, D. Environmental indicators for the assessment of quality of life. Intellectual Economics, [s. 1.], v. 9, p. 67-79, 2015. 